\title{
EFFECTIVE TEACHING THE PARTS OF SPEECH IN A SIMPLE SENTENCE
}

\author{
Miftahul Khairani \\ email.Meeftah_ul@yahoo.com \\ Lecturer of English Department UIN Syulthan Thaha Syaifuddin Jambi
}

\begin{abstract}
This articles argue that English Teachers should know all parts of speech. The research methodology is content analysis. The findings of research are before making sentences; English teachers must make a sense of the structure of a sentence. There are three major properties of sentence structure: Linearity, Hierarchy, Categorically. The structure of simple sentences basically patterned as Subject-Verb-Object (SVO). A sentence must be containing some parts of speech. Some parts of speech in the sentence could be shifted but its impact in the different meaning of sentences. In English, object can shift the subject but the meaning of the first sentence would be change. The sentence would have the same meaning though object and subject shift just in the passive form.
\end{abstract}

Key words: Parts of Speech, English Teachers

\section{INTRODUCTION}

English is one of the lenguages that used in the world. It is used not only in its country but also by others, as a lingua franca, especially for members of United Nations, English has been known by many people and also by Indonesian and In Indonesia, English is considered as a foreign language. Since it is very important, Indonesians must be able to use English in making cooperation with the other countries such as; in social communities, economies and political policies. For that reason, Indonesian government takes to improve the capability of its citizen in mastering Englsih. It means that English is being taught in schools, from elementary to university level. 
Mastering use a language can be done by studyin all of things relating to elements of language. One of them is grammatical structure. So, to mastering English, we should study its grammatical structure. According to Harris, grammar is one of the very important elements that help one to learn more abou the given language. ${ }^{1}$

Mulkan asserts that every language consists of three elements. First, sounds element that differ one to another language. Sounds that same for two languages not always has the same pronunciation. /p/ sound of pensil in Indonesia is not same with first sound of pencil in English./p/ sound in the first word of English is followed by explosion aound while in Indonesia is not. The explosion is same with /b/ sound in Javanese, especially in East Java example; banyu. On the other way, /p/ sound in Javanese is not followed by the explosive sound. Indonesia and Javanese words that begin by /p/ sound can be heard strange if uttered by English speaker.

Second, is vocabulary of language. Vocabulary wil be in progressing deal with the necessity or being omitted. As that, it is difficult to determine the accurate quantity vocabularies of a language. And it is also difficult to determine how many English words that should be learned.

Last, is grammar. It is used to arrange the words, words formation and relation among the words. In some years ago grammar often considered by the very tiresome aspect in language learning process. The negative thinking is derived from conventional teaching system that practiced in Europe in Latin subject. Latin is the very important subject at that time all over of Europe. Grammar is language formulas that must be learned by heart. Besides, grammar includes th "right" and "wrong" about rule of language. There is no acquisition of language because Latin has no its speaker anymore. Latin is being learned just for scientific necessity not for active communication. No wonder that grammar subject become a ghost for the students because it is difficult and tiresome. Latin teaching tradition continued in the beginning of teaching Modern European language, memorizing formulas, a long explanation about right and wrong and less acquisition practice of the language, effecting the English teaching process in Indonesia formerly still today. ${ }^{2}$

So formula of grammar that placed in the last of unit being comprehend easily by students after they making a sense and practice the utility of elements. Inductive approach will be better than deductive that often used in grammar in the past. Elements that used to teach by deductive way described into mathematical language

1 David P. Harris, Testing Engslish as a Second Language, (McGraw Hill: United States of America, 1969), p. 9.

${ }^{2}$ M.R. Mulkan, Kita dan Bahasa Inggris, (Jakarta:Balai Pustaka, 1987) p. 180-181. 
formula or into definition. Then, rigid definition or formul followed by examples and exercises that relates to the main problem.

Studying grammar is not the aim of teaching English. Grammar subject is just one of the language elements in English that need to be mastered to reach out the object, namely English acquisition and function of communication. One of the most important elements of that English is word. Hall elucidates that words have traditionally been classified into parts of speech. ${ }^{3}$ Brooks said that after makin a sense about the basic patterns, it is necessary to classify words to the role they play in the stream of speech. ${ }^{4}$ He makes four classes; things, action, quality and function words. So that, Hall mentioned nouns, adjectives, verbs and adverbs as the largest groups of parts of speech.

This research is focused on formal function of English. It means that the writer analyzes about English grammar, especially parts of speech. It is as an input for English learning process. We should get more information about parts of speech. At least, we are able to make a simple sentence by putting some of them in sentence. This article discusses; what are parts of speech; what structure of a simple sentence is; and what are the basic parts of speech in a simple sentence.

\section{LITERATURE DISCUSSION}

The writer could not find yet the research that focused on these problems. Before writing, the writer has conducted a literary observation to raise the problems up. There are many books that used in this research but the explanations still being separated into each other. In Grammar for Use by Eugene Hall, just informs classification of parts of speech in a simple sentence. While Burton in his book "Mastering English Language", explains what is a sentence. Some opinion from other books also inform separately both parts of speech and a simple sentence. So, writer tries to join and analyze them together.

In this research, the writer uses primary data as follows: 1) Grammar for Use by Eugene J. Hall; 2) Building English Sentences with Adverbs by Eugene J. hall; 3) English Syntax by Roderick A. Jacobs; 4) Essentials of Englsih Grammar by Fuad Mas'ud; 5) Modern Englsih; a Practical Reference Guide by Marcella Frank; 6) High Schools English Grammar and Composition by Wren and Martin; 7) The Key to Englsih Vocabulary by a Division of the MacMillan Company; 8) Oxford Learner's Pocket

${ }^{3}$ Eugene J. Hall, Grammar for Use, (Jakarta Binarupa Aksara, 1993), p. 8.

${ }^{4}$ Nelson Brooks, Language and Language Learning, (Hartcourt, Brace and World Inc, United States, 1982), p. 53-54 
Dictionary by Oxford University Press; 9) How to Teach English by Jeremy Harmer; 10) Bahasa Inggris yang Baik dan Benar bu Sugeng Panut; 11) Improving English Skill by Desmond W. Evans; 12) Building Englsih Sentence with Adjectives by Eugene J. Hall; 13) Beginning Syntax by Linda Thomas.

\section{RESEARCH METHODS}

In this researcher in collecting data following steps must be done as follows: 1) find out the books that relate to the subject of the research; 2) writer classifies the books into primary or secondary; 3 ) the data will be collected from books completed by the sources; 4) checking data; 5 ) checking data by crossing check from one source to teach other to get a valid and reliable data; 6) classifying data based on research system that prepared.

In analyzing data, there are some steps as follows: 1) resume the data to comprehend and interpret it objectively; 2) find out pattern, theme and topic that will be discussed; 3) improve the data based on its content into primary or secondary data; 4) explain the data using direct or indirect techniques; 5) using thinking inductive and deductive, comparative, descriptive, and interpretative.

\section{RESEARCH RESULTS AND DISCUSSION}

\section{General Description of Pats of Speech}

These parts of speech have their own definition. The following are description of traditionally classification.

Noun is a word that descrives about name of things, person, or place. E.g. Tina, Chairs, Team. There are common noun and proper noun. A common noun is a name given in common to every person or thing of the same class or kind. A proper noun is the name of some particular person or place. E.g. Sita is a girl. Sita is a proper noun and Girls is a common noun. Common nouns include collective nouns and abstract nouns. Collective noun is the name of a number (collection) of person or things taken together and spoken of as one whole. E,g. a fleet, a collection of ships or vessels. An army, a collection of soldiers.

An abstract noun is usually the name of a quality, action, or state considered a part from the object to which it belongs, e.g. Quality: Goodness, kindness, whiteness, wisdom, bravery. Action: Laughter, movement, hatred, obedience. State: Childhood, youth, sleep, death, poverty. A distinction needs to be made between countable and uncountable nouns. As their name implies, we can count what the words in countable nouns, but we can't bount what the words in uncountable nouns. 
Countable nouns are the names of objects, people, etc. that we can count. E.g. we can say a pen, two pens, or a hundred of pens. Uncountable nouns are the names of things that we can't count, they mainly denote substances and abstract things. E.g. milk, sugar, coffee, sand. We can't say,"I like coffee" or "I'd like to buy some coffee." The word coffee is uncountable in the first and second sentence but will be uncountable if we say,"I'd like to buy a sachet of coffee". A noun that denotes a male living being is said to be of the Masculine Gender. Whereas, a noun that denotes a female living being is said to be of Feminine Gender, e.g. Masculine: Boy, Feminine, Girl.

A noun that denotes one person or thing is said to be in the Singular umber and more than one person or thing is Plural Number, e.g. Singular: Boy, Plural: Boys. Nouns which describe groups or organizations are called collective nouns, e.g. team, family. They can either be singular or plural depending on whether we are describing the unit or its member. "the team is strong", or"the team win the games."

Some collective nouns are formed by making adjectives behave like nouns and in this case they are always plural, e.g. the rich live in a glamour conditions". Compound nouns are used to nouns being one word. But English has many compound nouns, constructed from more than one word, e.g. "girlfriend, lemon tree". Not all compound words are nouns, however we can also compound adjectives, e,g. "dotted-skirt, goodlooking, white-crime".

Pronoun is a word that used to take the place of a noun, e.g. I have a dog. It is so funny. It used to replace a dog as a noun. We can use itu to replave the subject or object. Pronoun could be divided into several classes, namely: a) Demonstrative Pronoun is pronoun that used to point out the objects to which it refers, e.g. I see a book on the table. That book is thick; b) Reflexives Pronoun is pronoun that used to show the action done by the subject turns back,e.g. Tina pays the cloths by herself; c) Indefinite Pronoun is pronoun refer to person or things in a general way, but do not refer to any person or thing in particular, e.g. Some milk was split.

d) Personal Pronoun is pronoun that denotes the person, e.g. He is young; e) Possessive Adjectives Pronoun is pronoun that used with noun and $\overline{\text { do }}$ the work pf adjectives, e.g. those are your books; f) Possessive Pronoun is pronoun that denotes the possession, e.g. that book is hers; g) Impersonal Pronoun is pronoun that seems stand for noun whatever though this can be readily supplied from the verb, e.g. It is eight o'clock; h) Relative Pronoun, e.g, I met who lives in the next door; i) Reciprocal Pronoun is pronoun that state a reciprocal, e.g. Yudi and Indra are speaking each 
other; j) Interrogative Pronoun that used for asking questions, e.g. I don't know who you are.

Adjective is a word that used to describe a noun. There are many kinds of adjectives, namely: a) Adjective of Quality is adjective that shows the kind or quality of a person $r$ thing, e.g. She is a lazy girl; b) Adjective of Quantity is adjective that shows how much of a thing is meant, e.g. I have no money.

c) Adjective of Number show how many person or things are meant, or in what order a person or thing stands, e.g. My hand has five fingers; d) Demonstrative Adjectives that point out which person or thing is meant, e.g. Those boxes are empty; e) Interrogative Adjective that used in what, which and whose to ask questions, e.g. whose car is that?, which books are your?, What is that?

f) Proper Adjective derives from proper noun and usually point out nationality or language, e.g. Tono is a Javanese; g) Possessive Adjective is adjective that point out one thing or person from all, e.g. His uncle was died; h) Distributive Adjective is adjective that point out one thing or person from all, e.g. Every body is crying

Verb is a word that used to describe an action: a) Transitive Verb is a verb denotes an action that passes over from the doer or Subject to an object. Most Transitive Verb take a single object, e.g. My grandmother is reading a magazine; b) Intransitive Verb is a verb denotes an action that does not pass over to an object, or which expresses a state or being, e.g. Rice grows in the fertile soil; c) Finite Verb is a verb that can be change by tense, e.g. I work hard (infinitive); d) Auxiliary Verb is a verb that used by another verb to state an action or situation, e.g. She is very beautiful; e) Linking Verb is a verb that connects the Subject to its Complement, e.g. You look tired.

f) Regular Verb is verb that can be change by sense but it change regularly, e.g. Appear, Appeared, Appeared; g) Irregular Verb is a verb that can be change by tense irregularly, e.g. Begin, Began, Begun; h) Distransitive Verb is type of verb that requires two objects. One object is the familiar direct object, the other is an indirect object. ${ }^{5}$ Example, Ray told the children a story.

Adverb is a word that used to tell when, where, and how an action took a place: a) Adverb of Manner is adverb that used to state how an action takes a place, e.g. Alicia runs quickly; b) Adverb of Place is adverb that used to explain where an action takes a place, e.g. I keep my books in the bag; c) Adverb of Time is adverb that used to tell when an action takes a place, e.g. I will be there soon; d) Adverb of Degree is used to explain the degree of something, e.g. I love you very much; e) Adverb of Frequency

${ }^{5}$ Linda Thomas, Beginning Syntax, (Blackwell Publishers, Cambridge, 1995), p. 41. 
is used to state the frequency of an action, e.g. You always lie at me; f) Adverb of Quantity is used to tell the quantity of an action, e.g. I can speak Englsih just a little. G) Interrogative Adverb is used to ask something, e.g. Why did you come late?; h) Relative Adverb is used as connector in the sentence, e.g. I want to go out although it is raining,

Preposition means "placed before". It is usually come before a noun or pronoun to show relationship between person or things or actions. ${ }^{6}$ It also can come at the end of a clause with certain structure,e.g. I am lying on my bed.

Conjunction is a word that used to connect one part of speech to another or to join two clauses. We only use one conjunction for two clauses, e.g. "My mother like singing but can't dancing" Interjection is a word that often used to express a mood or to attract the attention of the listeners. It is ungrammatical and independent in a sentence, e.g. Oh my God!

\section{The Usage of Parts of Speech in a Simple Sentence}

There are some simple sentences will be examples. These sentences consists of parts of speech that need to be classified. Read the examples below:

\section{Sue ran across the road}

Sue as the subject of the sentence. It is a noun and can be changed into a pronoun "he". The action ran as an intransitive verb is a predicate and across is proper preposition of ran. But the road as the object can be put there to complete the sentence. The road is an adverb of place that used to answer "where" question of the action though ran not needs an object. It has one subject, one predicate and completed by an adverb.

\section{Hens lay eggs}

Subject of that sentence is Hen and can be change by its pronoun it. Lay as transitive verb is a predicate. It needs eggs as the object and eggs is a noun.

Both of the above sentences are patterned in Subject-Verb-Object (SVO). This is known as word order parameter of English language. As a simple sentence just have one infinite verb. A finite verb is an ordinary verb that can be changed by tens, need do, does or did as auxiliary verb in interrogative and negative sentence and also has six forms: infinitive, present participle, gerund, past tense, present tense and past participle. ${ }^{7}$ So both of the above sentences can be classified into simple sentences, by detailed.

${ }^{6}$ Collier, The Key to English Vocabulary, (Toronto: MacMillan, 1971), p. 12.

${ }^{7}$ Fuad Mas'ud, Essential Grammar of Englsib: a Practical Guide, (Yogyakarta: BPFE, 1992), p. 114. 

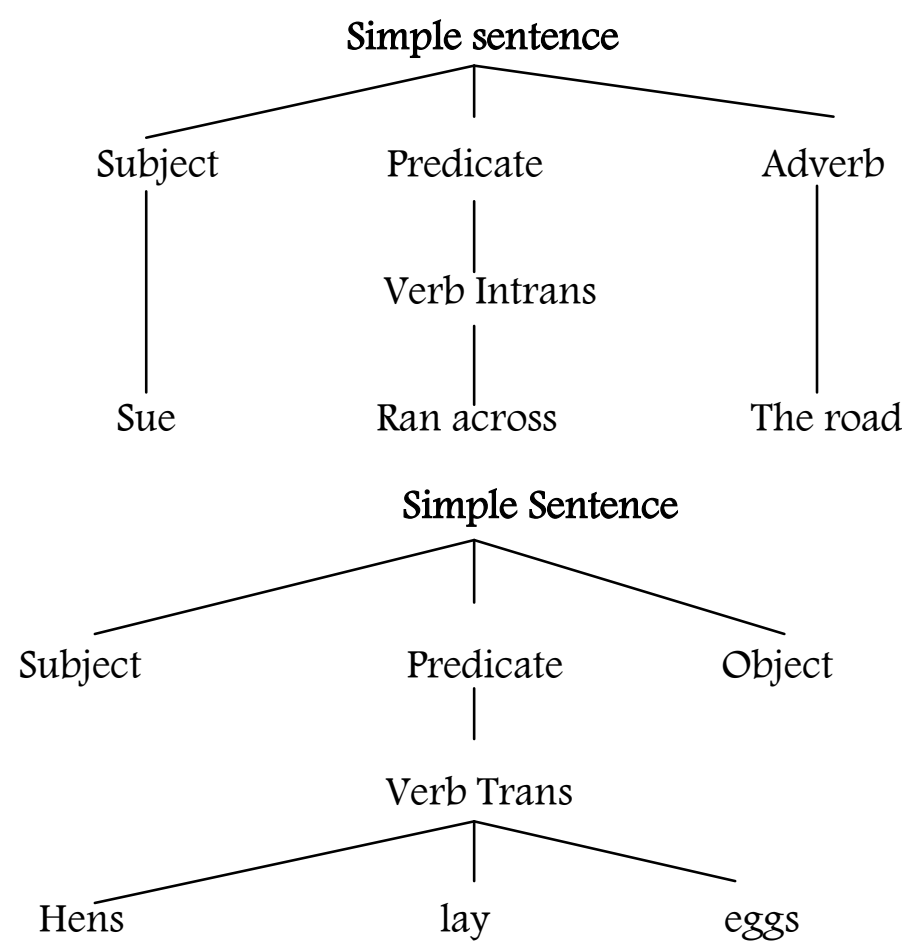

A simple sentence consists of subject and predicate. Subject can be noun or pronoun and the predicate by putting verb, adverb, or adjective. Here some sentences that uses to be as the predicate:

\section{Julia is pretty \\ Anton was a naughty boy in his childhood}

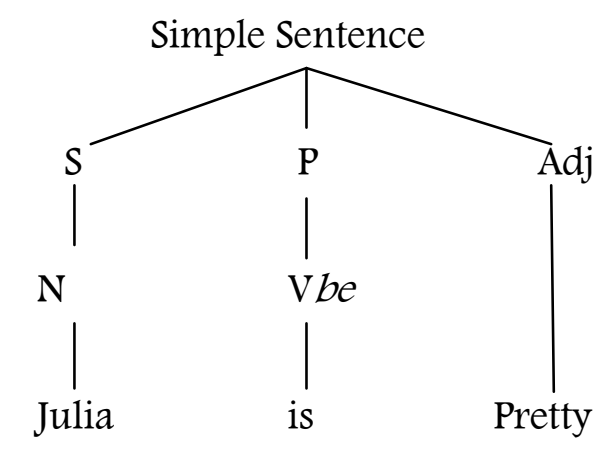

In the first sentence, Julia is noun as the subject while is a verb as predicate and pretty is the adjective to modify the subject. Pretty also called predicate adjective because it follow the verb be, Predicate adjective also follow the verbs of sense perception: smell, taste, sound, look, feel, appear and seem, like in the sentence "that tree looks very tall", and it is also follow verbs that indivate a change or lack of change in condtion: keep, stay, get, become, grow. Example, She grows younger every day. ${ }^{8}$

${ }^{8}$ Eugene J. hall, Building Englsih Sentences with Adjectives, Jakarta: Binarupa Aksara, 1993),p. 80. 


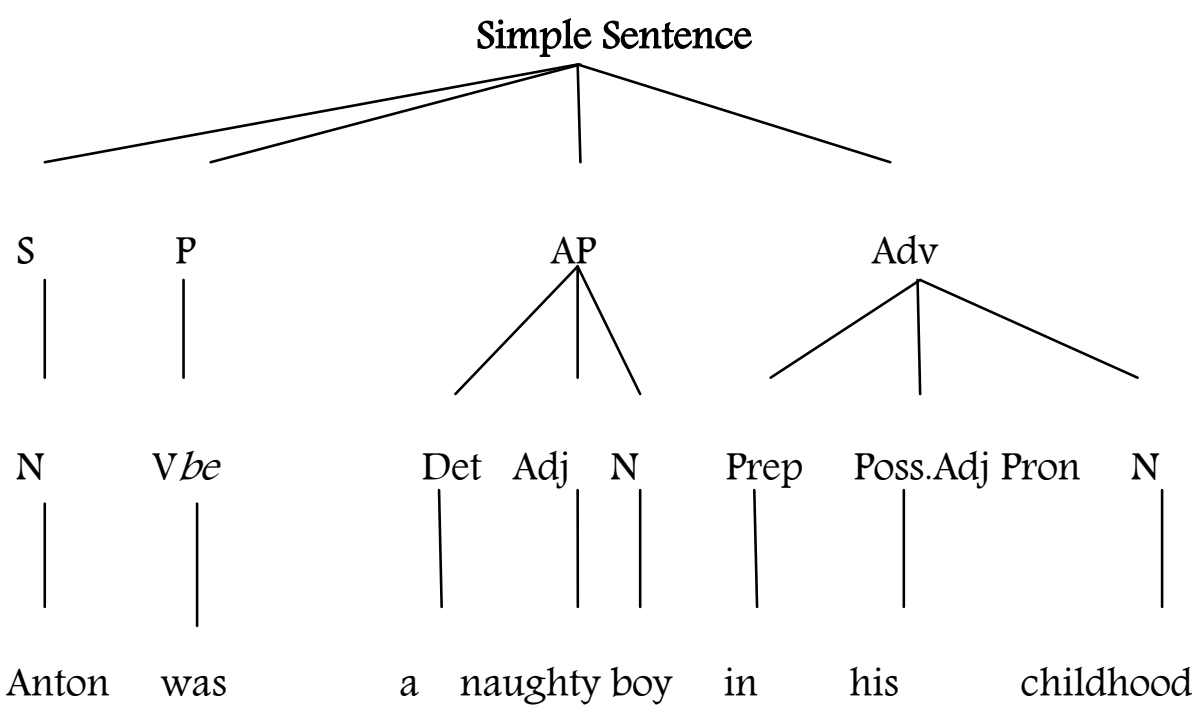

Anton in noun as the subject of second sentence, was is a verb in form of to be as predicate and spontaneously it needs naughty as an adjective and in his childhood is an adverb.

Based on the above examples can be concluded that a simple sentence consists of one subject and one predicate only. The subject can be a noun or pronoun and predicate can be transitive or intransitive verb, then an adjective and an adverb as the modifier.

\section{The Basic Parts of Speech in a Simple Sentence}

After examining those sentences, the writer concludes that some basic parts of speech are being contained in a simple sentence, they are:

1) Noun Iinclude pronoun to modify) as the subject of sentence.

2) Verb (transitive or intransitive and to be form) as the predicate of sentence.

3) Adjective that used if we take to be as the verb of sentence (we call it predicate adjective).

4) Adverb to modify the verb.

By using combination some parts of speech above, a simple sentence could be done. Notice that the sentence at least consists of a subject and a finite verb and be completed by putting adjective or adverb even an object.

Every simple sentence can be divided into two parts, as follows: 1) Subject, a part that names of the person and thing or about which something is said; 2) Predicate, a part that says something about the subject. In simple sentence, we used some parts of speech, namely: a) Noun (include pronoun) as the subject or object of the senence; b) Verb in finite form or be form; 3) Adjective as the predicate adjective if we take be as the predicate; 4) Adverb to modify the verb (telling something about verb). 
So we can say that the basic parts of speech that used in simple sentence are noun, verb, adjective and adverb. To make a simple sentence at least we could begin to make a sense them.

\section{CONCLUSION}

Based on result and discussion above can be concluded that: First, English Teachers should know all parts of speech. It is not too important to know the definition but they should be recognize them by examining its signals. So, Englsih Teachers could put them in appropriate place.

Before making sentences, English teachers must make a sense of the structure of a sentence. There are three major properties of sentence structure: Linearity, Hierarchy, Categorically. The structure of simple sentences basically patterned as Subject-Verb-Object (SVO).

A sentence must be contain some parts of speech. Some parts of speech in the sentence could be shifted but its impact in the different meaning of sentences. In English, object can shift the subject but the meaning of the first sentence would be change. The sentence would have the same meaning though object and subject shift just in the passive form.

\section{Effective Teaching the Parts of Speech}

Based on discussion about the classification parts of speech above, it can be usefull in effective teaching and learning about parts of speech in simple sentence. English teachers can do the steps below:

1) In teaching Englsih, the teachers should explain basic structure of sentence that construct a simple sentence.

2) Teacher should be able to explain four parts of speech namely: noun, verb, adjective and adverb for the beginner who want to be able to make a simple sentence.

3) English teacher to make sense four parts of speech that used in constructing a simple sentence, so English teacher could not confuse or worry in making the sentence.

Parts of speech: noun, verb, adjective and adverb should be taught to the students first in grammar because it facilities the students to make a simple English sentence. Among of them, verb could be the first. It is considered that verb has a functional word of sentence because it explains what subject is. While student had to know that noun as the name of thing and it can be placed as a subject or object of sentence. Both adjective and adverb are needed to modify subject and verb of sentence. 


\section{REFFERENCES}

Collier (1971), the Key to English Vocabulary, MacMillan, Toronto.

Hall,J. Eugene, (1993), Grammar for Use, Binarupa Aksara, Jakarta.

Hall, J. Eugnen, (1993), Building Englsih Sentences with Adjectives, Binarupa Aksara, Jakarta.

Harris, P. David, (1969), Testing Engslish as a Second Language, McGraw Hill, United States of America.

Linda Thomas,(1995), Beginning Syntax, Blackwell Publishers, Cambridge.

Mas'ud, Fuad,(1992), Essential Grammar of Englsih: a Practical Guide, BPFE, Yogyakarta.

Mulkan, M.R, (1987), Kita dan Bahasa Inggris, Balai Pustaka, Jakarta.

Nelson Brooks, (1982), Language and Language Learning, Hartcourt, Brace and World Inc, United States. 